\title{
Synthesis of ZnO Nanostructures by Microwave Irradiation Using Albumen as a Template
}

\author{
T. Prakash, ${ }^{1}$ R. Jayaprakash, ${ }^{1}$ G. Neri, ${ }^{2}$ and Sanjay Kumar ${ }^{3}$ \\ ${ }^{1}$ Nanotechnology Laboratory, Department of Physics, Sri Ramakrishna Mission Vidyalaya College of Arts and Science, \\ Coimbatore, Tamil Nadu 641020, India \\ ${ }^{2}$ Department of Electronic Engineering, Chemistry and Industrial Engineering, University of Messina, 98166 Messina, Italy \\ ${ }^{3}$ Department of Physics, B. R. Ambedkar Bihar University, Muzaffarpur, Bihar 842001, India
}

Correspondence should be addressed to R. Jayaprakash; jprakash_jpr@rediffmail.com

Received 10 January 2013; Accepted 1 February 2013

Academic Editor: Amir Kajbafvala

Copyright (C) 2013 T. Prakash et al. This is an open access article distributed under the Creative Commons Attribution License, which permits unrestricted use, distribution, and reproduction in any medium, provided the original work is properly cited.

$\mathrm{ZnO}$ nanostructures have been successfully prepared by a microwave irradiation method. The role of albumen as a template in addressing the size and morphology of $\mathrm{ZnO}$ has been investigated by X-ray diffraction (XRD), Fourier transform infrared spectroscopy (FT-IR), thermogravimetric analysis (TG-DTA), scanning electron microscopy (SEM), and transmission electron microscopy (TEM) techniques. A heterogeneous mixture of $\mathrm{Zn}(\mathrm{OH})_{2}$ and $\mathrm{ZnO}$ was obtained in absence of albumen. Pure $\mathrm{ZnO}$ nanostructures, consisting of rod- and whisker-like nanoparticles embedded in a sheet matrix, were obtained in the presence of albumen. Optical and photoluminescence (PL) properties of the synthesized samples were also compared. Results obtained indicate that the microwave-assisted method is a promising low temperature, cheap, and fast method for the production of $\mathrm{ZnO}$ nanostructures.

\section{Introduction}

Recently, metal oxides which exhibit morphologies at the nanoscale $(<100 \mathrm{~nm})$ have become increasingly important. One of them is $\mathrm{ZnO}$, a wide band gap n-type semiconductor $(3.37 \mathrm{eV})$ with large exciton binding energy of $(60 \mathrm{meV})$ at room temperature, which has attracted much attention due to its unique properties. $\mathrm{ZnO}$ nanoparticles have found numerous applications, such as in gas sensors [1], transparent electrodes [2], pH sensors [3], biosensors [4], acoustic wave devices [5], and UV photodiodes [6].

Up to now, a number of investigations have focused on the synthesis of nano- and microarchitectures through different methods like hydrothermal [7], sol-gel [8], electrochemical deposition [9], and vapor-phase process [10]. Previous studies on the microwave radiation synthesis of $\mathrm{ZnO}$ with a variety of morphologies, such as nanowires [11], nanorods [12], nanoneedles [13], hollow structures, and self-assembled architectures [14], were widely reported.
In this work, we synthesized $\mathrm{ZnO}$ nanostructures via a microwave irradiation method in the presence of albumen as a biotemplate. Microwave irradiation as a heating method has found a number of applications in chemistry. The utilization of microwave irradiation in the preparation of nanoparticles has been reported in recent years [15]. Compared to the conventional methods, the microwave synthesis has the advantages of producing small particle size metal oxides with high purity owing to short reaction time [15-19]. Due to the "in situ" mode of energy conversion, the microwave heating process is fundamentally different from conventional heating processes. Heat will be generated internally within the material, instead of originating from external sources. By means of this method, many functional materials and compounds with novel structures and properties have been obtained [20]. In recent studies, it has been shown that nanoparticles, such as $\mathrm{Co}_{3} \mathrm{O}_{4}$ [21], $\mathrm{LiMn}_{2-x} \mathrm{Cr}_{x} \mathrm{O}_{4}$ [22], $\mathrm{SnO}_{2}$ [23] $\mathrm{Ce}_{1-x} \mathrm{Gd}_{x} \mathrm{O}_{2-1 / 2 x}$ [24], $\mathrm{MgO}$ [25], $\mathrm{ZnO}$ [26], and $\mathrm{TiO}_{2}$ [27], can be prepared by the microwave synthesis process. Though the application 


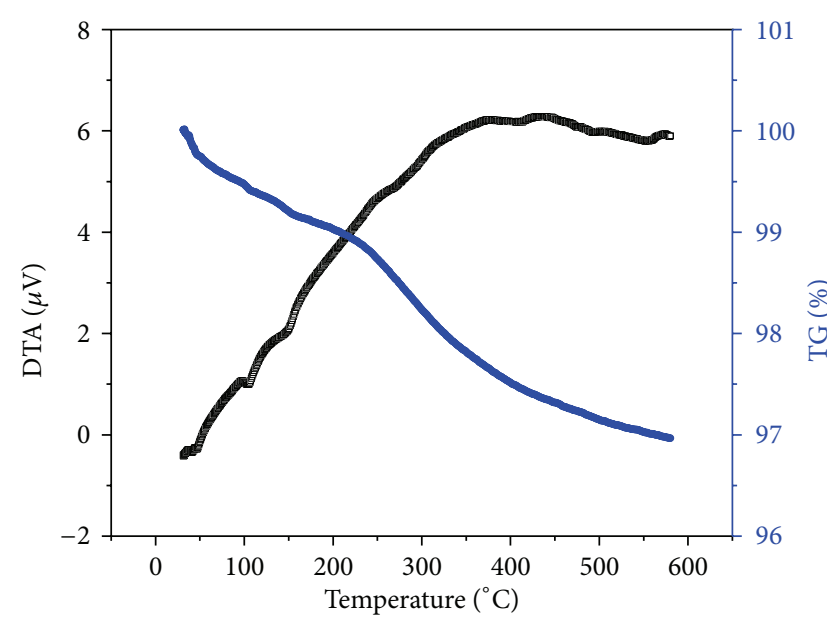

(a)

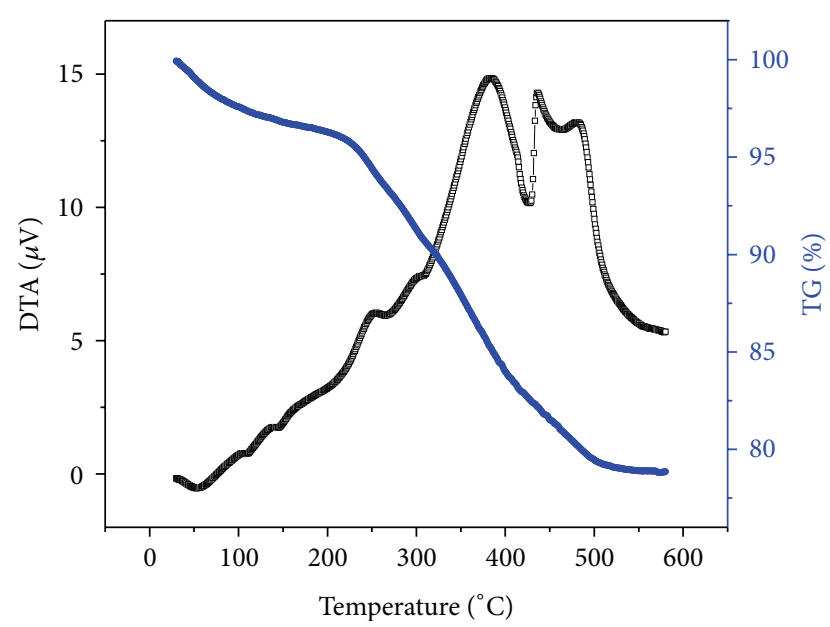

(b)

FigURE 1: TG-DTA analysis of microwave synthesized samples: (a) sample A, (b) sample B.

of microwave irradiation in synthetic chemistry started in 1980 s, only in the recent years, its use has provided a new, efficient, and environmentally benign methodology for the synthesis of various metal oxide nanoparticles of diverse morphologies and sizes. These radiations have unique properties like homogenous volumetric heating, which causes heating directly inside the sample, high reaction rate, selectivity, and increased product yield. Moreover, it is an energy saving process $[14,28,29]$.

The process here proposed to synthesize $\mathrm{ZnO}$ nanostructures by a microwave-assisted process is simple, cheap, and fast and is characterized by a low synthesis temperature $\left(130^{\circ} \mathrm{C}\right)$. As compared to conventional heating, microwaves cause the uniform distribution of temperature between the surface and the bulk material thereby leading to the fast formation of $\mathrm{ZnO}$ nanoparticles [30, 31]. Another advantage is that no postannealing process is necessary to obtain $\mathrm{ZnO}$ crystalline nanometer-sized structures compared to other microwave irradiation methods reported in the literature $[32,33]$. To investigate the role of template in the synthesis of $\mathrm{ZnO}$ nanostructure by this method, a comparative study has been carried characterizing the products obtained in the presence or not of albumen as a biotemplate. The $\mathrm{ZnO}$ nanomaterials obtained were thoroughly characterized through $\mathrm{X}$-ray diffraction (XRD), Fourier transform infrared spectroscopy (FT-IR), thermogravimetric analysis (TG-DTA), scanning electron microscopy (SEM), and transmission electron microscopy (TEM) techniques. Furthermore, their optical properties were assessed by UV-Vis DRS spectra and photoluminescence (PL) measurements.

\section{Experimental Procedure}

2.1. Materials. Zinc nitrate $\mathrm{Zn}\left(\mathrm{NO}_{3}\right)_{2}$ and ammonia solution $\left(\mathrm{NH}_{4} \mathrm{OH}\right)$ were supplied from (Merk, 98\%) Mumbai, India. All the chemicals were of analytical grade and used as received without further purification. The albumen, extracted from white part of egg, was used for the synthesis. Double distilled water was used through the experiments.

2.2. Synthesis. The synthesis of $\mathrm{ZnO}$ nanostructures by the microwave irradiation method was carried out as follows. First, a $0.1 \mathrm{M}$ of zinc hydroxyl solution was prepared by dissolving zinc nitrate $\left(\mathrm{Zn}\left(\mathrm{NO}_{3}\right)_{2}\right)$ in deionized water. Then $\mathrm{pH}$ of the solution was maintained at 8 by adding liquid ammonia solution dropwise. The resulting product was filtered and washed with double distilled water and ethanol until it became free from impurities. The precipitate was irradiated for 5 minutes in household microwave (radiation frequency $2.45 \mathrm{GHZ}$, Power up to $1 \mathrm{KW}$ ) with convection mode, giving a white product. Finally the sample was dried at $130^{\circ} \mathrm{C}$ (sample A) for 5 hours.

The same experimental procedure was followed for the synthesis of $\mathrm{ZnO}$ nanostructures carried out in the presence of albumen (sample B), by adding drop by drop $5 \mathrm{~mL}$ of freshly extracted albumen, mixed with $25 \mathrm{~mL}$ of deionized water and stirred, to $0.1 \mathrm{M}$ zinc hydroxyl solution.

2.3. Characterization. The sample microstructure was analyzed by X-ray diffraction (XRD) using a Bruker AXS D8 Advance instrument and the monochromatic $\mathrm{CuK}_{\alpha 1}$ wavelength of $1.5406 \AA$. The average crystalline size of the crystallites was evaluated using Scherrer's formula, $d=K \lambda / \beta \cos \theta$, where $d$ is the mean crystalline size, $K$ is a grain shape dependent constant (0.9), $\lambda$ is the wavelength of the incident beam, $\theta$ is a Bragg reflection angle, and $\beta$ is the full width at half maximum (FWHM) of the main diffraction peak. The sample morphology was observed by scanning electron microscopy (SEM), using a JEOL 5600LV microscope at an accelerating voltage of $10 \mathrm{kV}$. High resolution transmission electron microscopy (HRTEM) and selected-area electron diffraction (SAED) were recorded on a Tecnai G20-stwin 


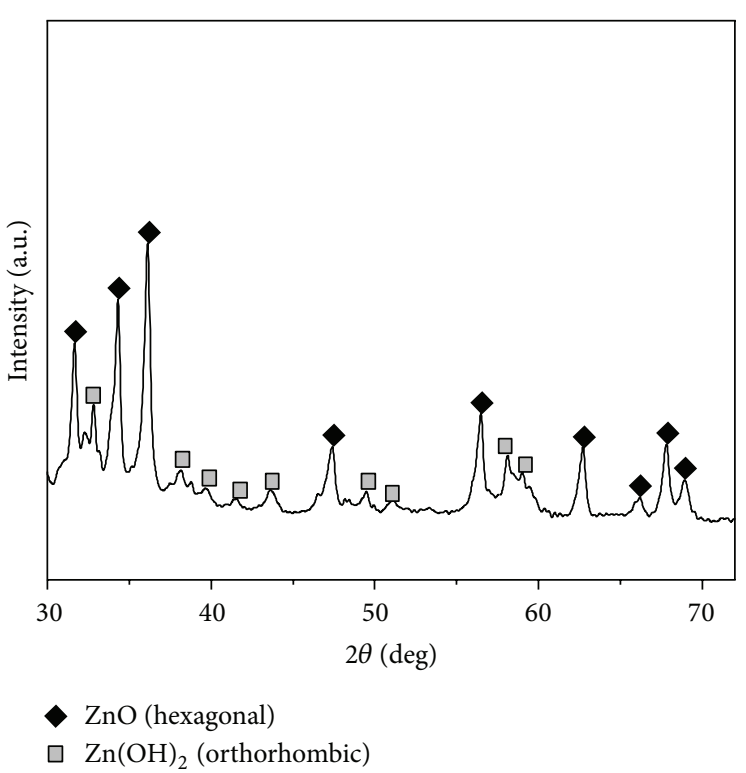

(a)

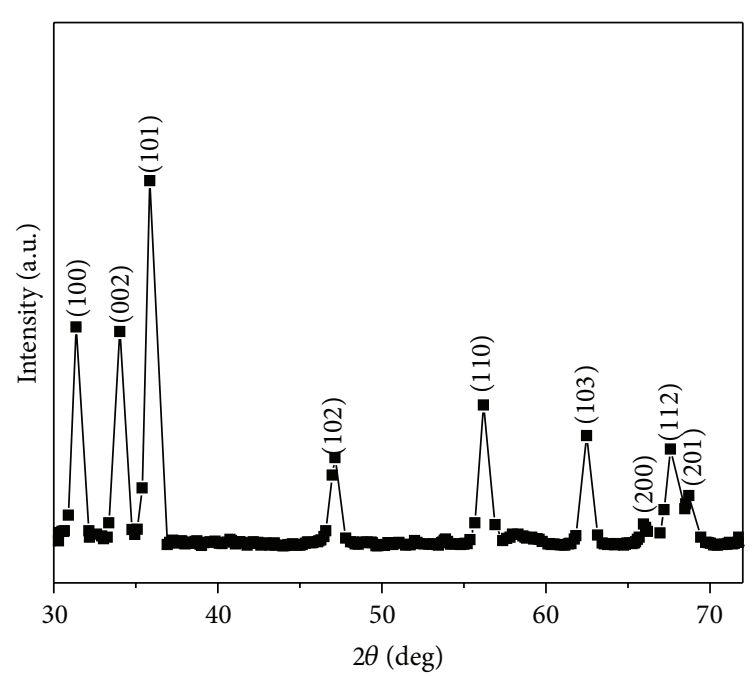

(b)

FIGURE 2: XRD analysis of microwave synthesized samples: (a) sample A, (b) sample B.

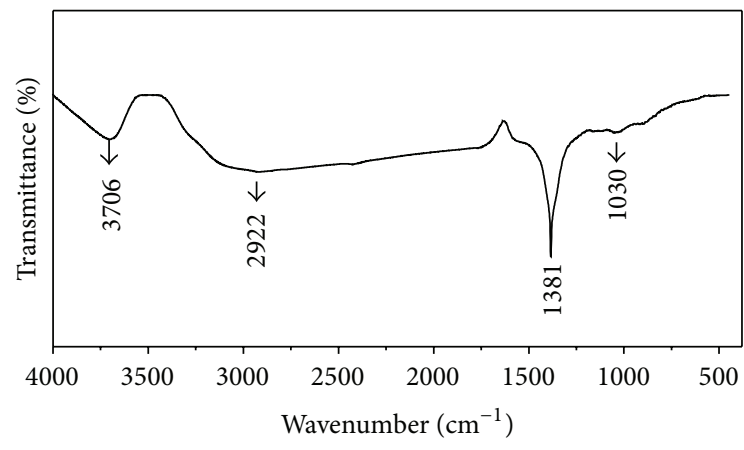

(a)

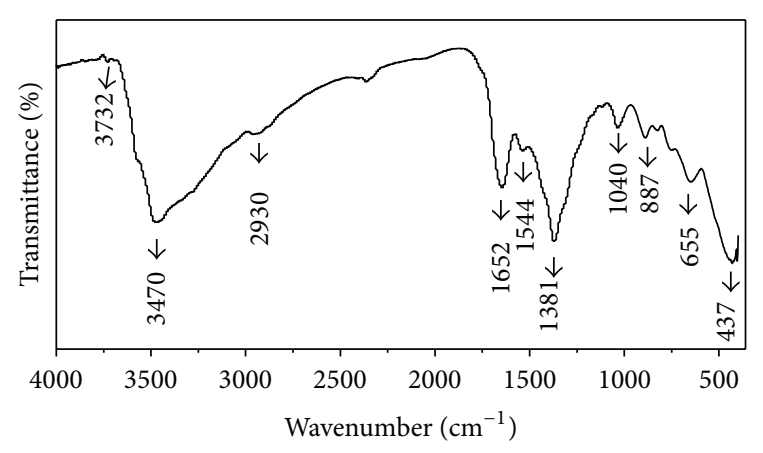

(b)

FIGURE 3: FT-IR spectra of microwave synthesized samples: (a) sample A, (b) sample B.

using an accelerating voltage of $200 \mathrm{kV}$. The Fourier transform infrared spectra (FT-IR) of the samples were recorded by using a Nicolet 5DX FTIR spectrometer. Thermal analysis was carried out by using a thermogravimetric and differential scanning calorimeter apparatus (TG-DSC Netzsch-Model STA 409PC). The analyses were carried out with a heating rate of $10^{\circ} \mathrm{C} / \mathrm{min}$ in static air up to $800^{\circ} \mathrm{C}$. The ultraviolet (UV) spectrum of the $\mathrm{ZnO}$ samples was recorded on a Perkin Elmer UV-visible DRS spectrophotometer. The room-temperature PL spectrum was performed on a spectrofluorometer instrument (JY Fluorolog-FL3-11).

\section{Results and Discussion}

\subsection{Morphological and Microstructural Analysis}

3.1.1. Thermogravimetric Analysis. The thermal behavior of $\mathrm{ZnO}$ samples synthesized has been first investigated by TGDTA. Figure 1(a) shows the TG-DTA curves of sample A.
The weight loss monitored in the range $25-600^{\circ} \mathrm{C}$ is low and has been calculated to be less than $3.3 \%$ in total. This weight loss is ascribed to the removal of absorbed water molecules and ethanol and the loss of hydroxyl ions. The final step at higher temperature is attributed to the burnout of organic species still remained in the dried powder. By focusing the attention on sample B, TGA indicated that the weight loss is higher (about $20 \%$ in total). The first weight loss in the temperature range between $25^{\circ} \mathrm{C}$ and $150^{\circ} \mathrm{C}$ is ascribed to the removal of adsorbed water molecules. The second weight loss in the range between $230^{\circ} \mathrm{C}$ and $520^{\circ} \mathrm{C}$ comes from the decomposition of the organic template, which is also confirmed by the exothermic peak at about $384^{\circ} \mathrm{C}$ in the DTA curve.

3.1.2. X-Ray Diffraction. The phase identification of the synthesized $\mathrm{ZnO}$ nanostructures was determined by X-ray diffraction (XRD). Figures $2(a)$ and 2(b) show the XRD 


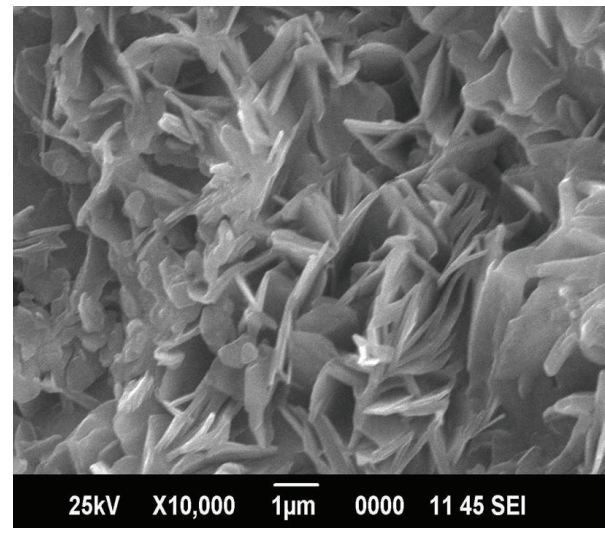

(a)

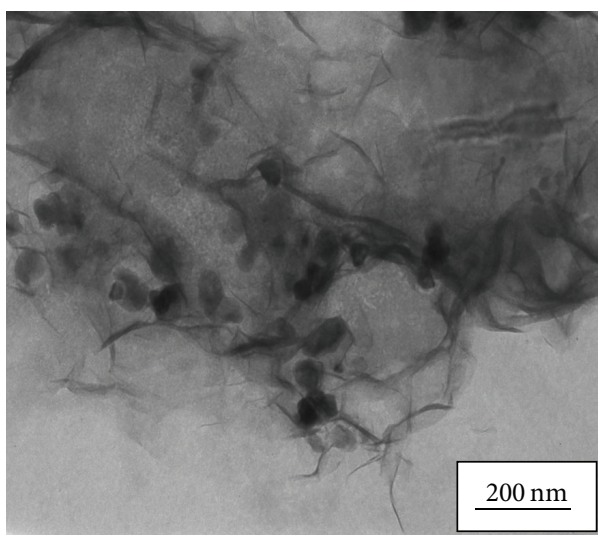

(b)

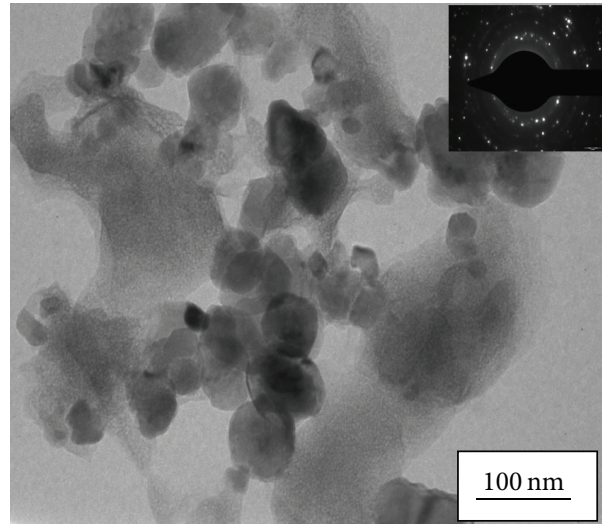

(c)

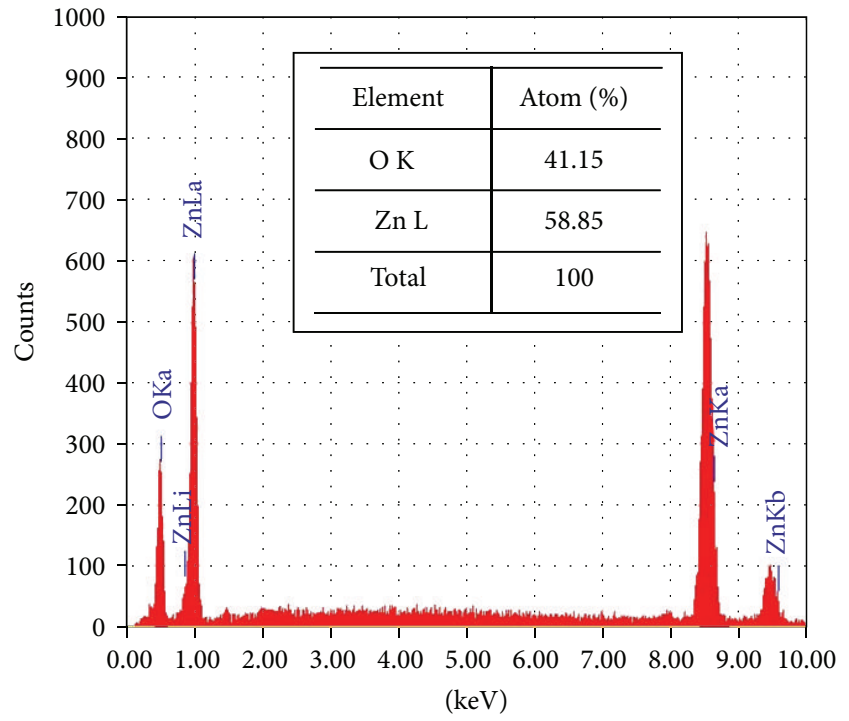

(d)

FIgURE 4: SEM and TEM micrographs of sample A. (a) SEM image, (b) and (c) TEM images of the sheet-like and spherical-like ZnO nanostructure, and (d) EDX analysis. Inset in Figure (c) shows the SAED pattern.

patterns of both samples. In Figure 2(a), XRD of sample A indicated that two phases, like $\mathrm{ZnO}$ hexagonal wurtzite phase structure (JCPDS number 897102) and $\mathrm{Zn}(\mathrm{OH})_{2}$ orthorhombic phase structure (JCPDS number 890138), are present. On the basis of diffraction peaks intensity, $\mathrm{ZnO}$ is the predominant phase. According to Scherrer's equation, the average particle size of $\mathrm{ZnO}$ nanoparticles is about $29 \mathrm{~nm}$.

Figure 2(b) shows the XRD pattern of sample B. The diffraction planes (100), (002), (101), (102), (110), (103), (200), (112), and (201) in the patterns can be perfectly indexed to the hexagonal wurtzite phase structure (JCPDS number 897102). Also no diffraction peaks corresponding to $\mathrm{Zn}, \mathrm{Zn}(\mathrm{OH})_{2}$, and other impurities are observed. The value of lattice parameters ( $a=3.2896 \AA$ and $c=5.2624 \AA$ ), as calculated by the XRD data, is in good agreement with those reported by other authors [33]. The average particle size of $\mathrm{ZnO}$ is estimated to be around $14 \mathrm{~nm}$.
$\mathrm{XRD}$ analysis indicates that the pure $\mathrm{ZnO}$ phase is obtained only in the presence of albumen. Furthermore, the average particle size of $\mathrm{ZnO}$ phase is markedly lower. It can be supposed that, in the formation processes in absence of albumen, the zinc hydroxide species was first produced step by step by the reaction between the $\mathrm{Zn}$ species and the hydroxyl ions coming from dissociation of hydrated ammonia molecules, and then in a consecutive reaction $\mathrm{ZnO}$ nanoparticles are formed. In the presence of template molecules, it appears that this second reaction is strongly promoted; so all initial zinc hydroxide species are transformed into $\mathrm{ZnO}$.

3.1.3. Fourier Transform Infrared Spectroscopy. Figure 3(a) shows the typical FT-IR spectrum of sample A. The broad peak at $3706 \mathrm{~cm}^{-1}$ corresponds to the vibrational mode of $\mathrm{O}-\mathrm{H}$ bond, indicating the presence of zinc hydroxide. The 


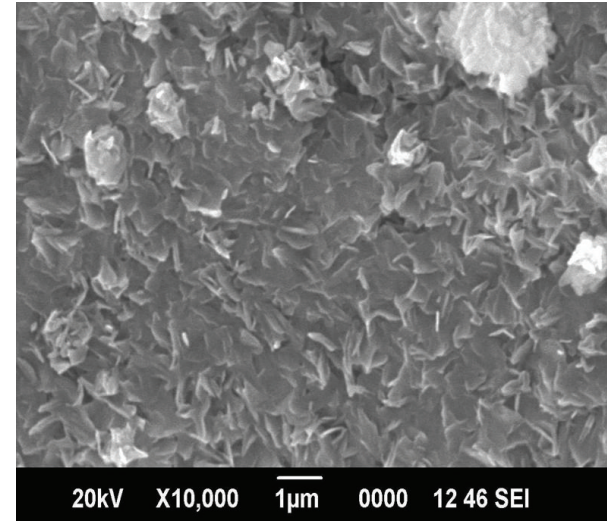

(a)

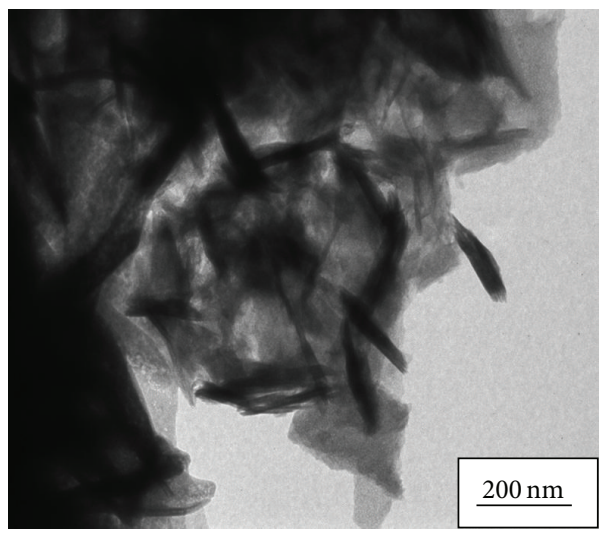

(b)

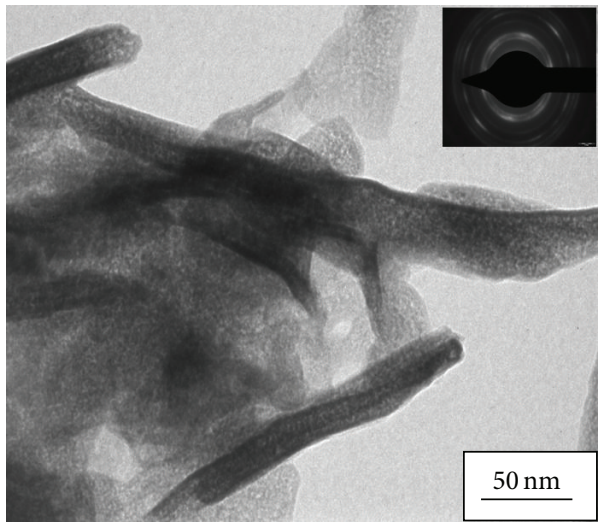

(c)

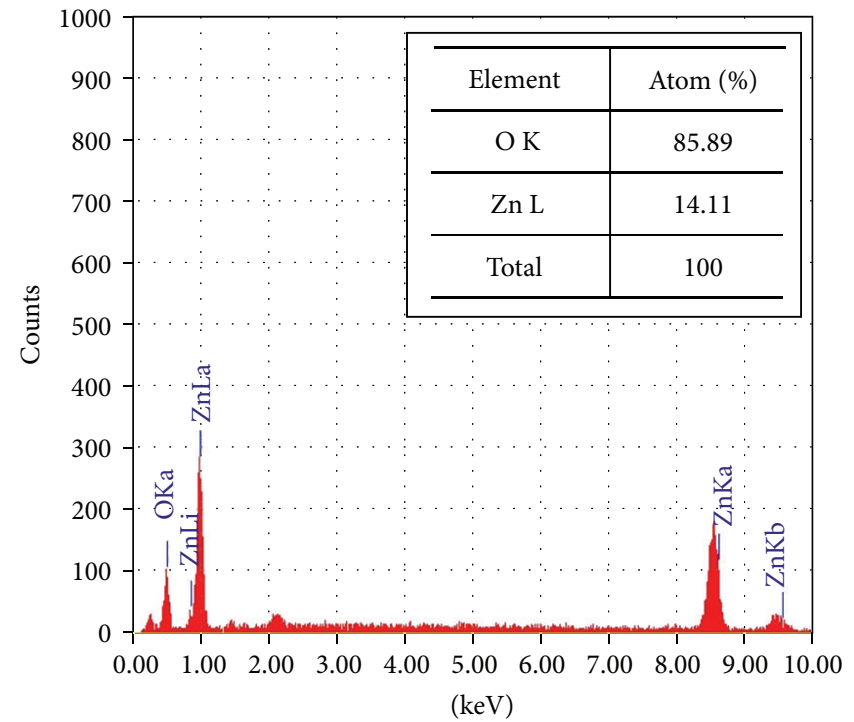

(d)

FIgURE 5: SEM and TEM micrographs of sample B. (a) SEM image, (b) and (c) TEM images of the whisker-like and rod-like ZnO nanostructure, and (d) EDX analysis. Inset in Figure (c) shows the SAED pattern.

stretching mode of vibrations in asymmetric and symmetric $\mathrm{C}=\mathrm{O}$ bonds that is observed at $1381 \mathrm{~cm}^{-1}$ is associated with residual organic impurity in the dried powder as suggested by TG-DTA analysis.

In the spectrum of sample B (Figure 3(b)), the appearance of a sharp band at $437 \mathrm{~cm}^{-1}$ in the FT-IR spectrum, characteristic for the $\mathrm{Zn}-\mathrm{O}$ stretching vibration [34], confirms the presence of well-crystallized $\mathrm{ZnO}$. Additionally broad absorption peaks centered at around $3470 \mathrm{~cm}^{-1}$ and $1652 \mathrm{~cm}^{-1}$ are caused by the $\mathrm{O}-\mathrm{H}$ stretching of the absorbed water reabsorption during the storage of the sample in ambient air [35]. The absence of features at $3706 \mathrm{~cm}^{-1}$ is an indication of the absence of $\mathrm{Zn}(\mathrm{OH})_{2}$ phase on this sample. In this sample are also seen the signatures of the organic template. The broad peak at $3470 \mathrm{~cm}^{-1}$ is in fact due to superimposition of $\mathrm{N}-\mathrm{H}$ stretching of amide group at $3449 \mathrm{~cm}^{-1}$ of the biotemplate and $\mathrm{O}-\mathrm{H}$ stretching mode of water molecules. Also some of the absorption bands in the range $1000-1600 \mathrm{~cm}^{-1}$ are due to $\mathrm{C}=\mathrm{O}$ and $\mathrm{C}=\mathrm{C}$ stretching vibrational modes of albumen, as well the weak peaks located at $2930 \mathrm{~cm}^{-1}$ are due to symmetric and asymmetric C-H bonds, respectively [36]. A very small band originated at $887 \mathrm{~cm}^{-1}$ is probably due to the carbonate moieties which are generally observed when FT-IR samples are measured in air $[37,38]$.

3.1.4. Scanning and Transmission Electron Microscopy. SEM and TEM images of sample A are reported in Figure 4. SEM analysis shows extensive sheet-like nanostructure where spherical-shaped particles are also present. TEM analysis evidences clearly this composite structure and the large diameter distribution of the spherical-shaped nanoparticles. No attempt has been made to assign the two phases present, $\mathrm{ZnO}$ and $\mathrm{Zn}(\mathrm{OH})_{2}$, to each of these nanostructures. The thickness of the sheets and spherical particles is in the range of about $13-50 \mathrm{~nm}$. The SAED pattern taken from one of 


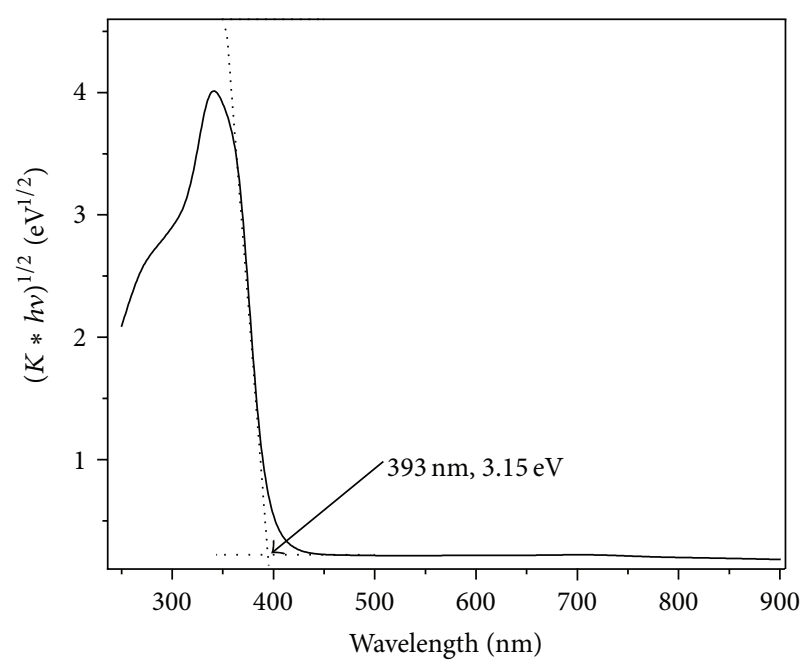

(a)

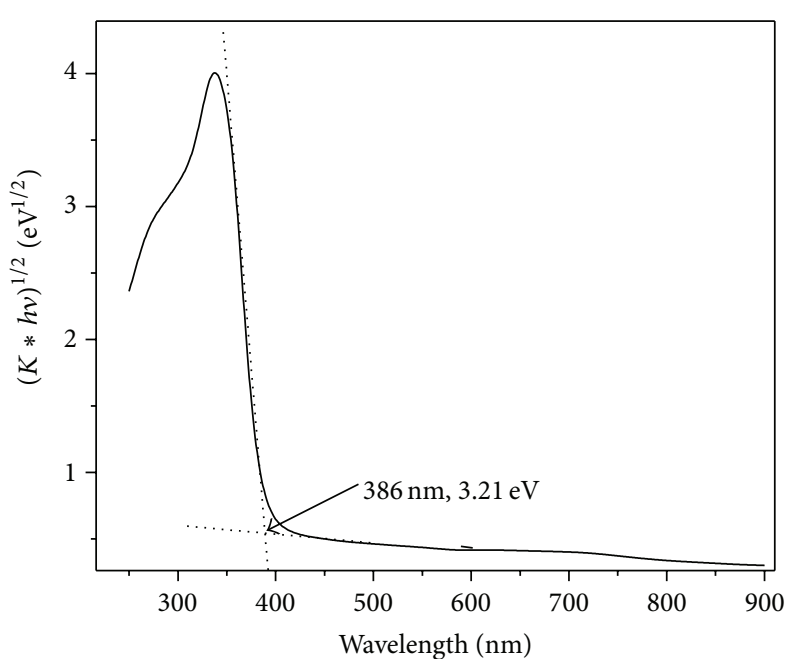

(b)

Figure 6: UV-Vis DRS of the typical ZnO nanoparticles: (a) sample A, (b) sample B. Extrapolation of the linear portion to the photon energy axis to obtain the $E_{g}$ value is shown.

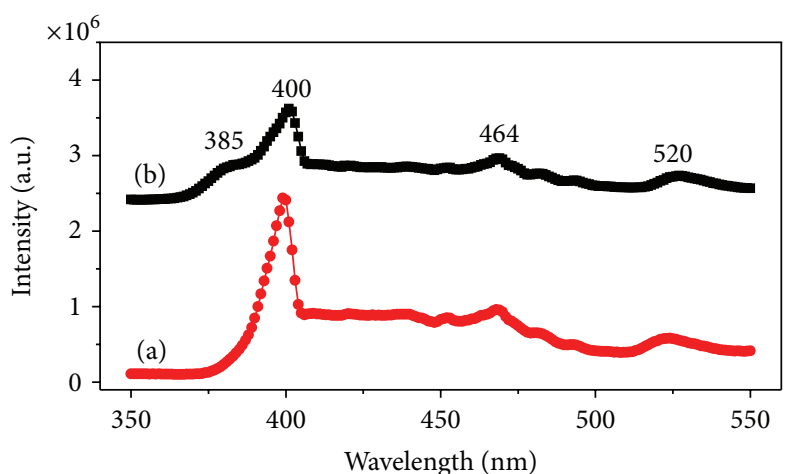

Figure 7: PL spectra of (curve a) sample A and (curve b) sample B.

the particles is shown in the inset, and it further confirms the crystalline nature of the sample. In addition, the EDS spectrum of the sample confirms the presence of $\mathrm{Zn}$ and $\mathrm{O}$ in sample without any other element contamination. The atomic percent ratio of $\mathrm{O}$ and $\mathrm{Zn}$ in dried sample is $41.15: 58.85$, which might indicate that there is a small content of oxygen vacancy defects on the surface of as-obtained product.

Figure 5 shows SEM and TEM images of sample B. SEM analysis shows that this sample is characterized by a more uniform surface sheet-like nanostructure. TEM analysis revealed the presence of nanowhiskers and nanorods of different length and diameter embedded within the sheet matrix. The thickness of the nanorods and nanowhiskers is in the range of about $10-57 \mathrm{~nm}$. The SAED pattern of $\mathrm{ZnO}$ nanostructures further confirms the crystalline nature of the sample. EDS analysis reports that the atomic percent ratio of $\mathrm{O}$ and $\mathrm{Zn}$ in the dried sample is $85.59: 14.11$, which might indicate that there is a larger content of oxygen on the surface with respect to sample A.
3.2. Optical Properties. In order to determine the precise value of optical band gap UV-visible DRS of the $\mathrm{ZnO}$ nanoparticles in samples A and B, we used the optical absorption method on reflectance spectrum. The reflectance values were converted to absorbance by application of the Kubelka-Munk function [39-42]. The Kubelka-Munk theory is generally used for analyzing the diffuse reflectance spectra obtained from weakly absorbing samples. The Kubelka-Munk formula can be expressed by the following relation [43]:

$$
K=\frac{(1-R)^{2}}{2 R},
$$

where $K$ is the reflectance transformed according to KubelkaMunk and $R$ is the reflectance (\%).

The relationship $(k * h 9)^{1 / 2}=f(h * 9)$ is shown in Figures 6(a) and 6(b). The $E_{g}$ value can be obtained by extrapolating the linear portion to the photon energy axis. The reflectance shoulder onset peaks are located at $393 \mathrm{~nm}$ and $386 \mathrm{~nm}$ corresponding to the band gaps of $3.15 \mathrm{eV}$ and $3.21 \mathrm{eV}$, respectively. The $E_{g}$ values are smaller than that of $3.3 \mathrm{eV}$ reported for single crystalline $\mathrm{ZnO}$ samples. On comparison with $\mathrm{ZnO}$ nanoparticles prepared by other methods, $\mathrm{ZnO}$ nanoparticles are obtained by this microwave irradiation method showing larger band gap energy. It is well known that the difference in the band gap is related to the presence of vacancies and dopants [44]. The red shift of the band gap energy also relates to structural morphologies, particle size, and surface microstructures [45]. Then, the higher value of band gap of the sample B synthesized in the presence of albumen can be attributed to a minor amount of defects, due essentially to its more ordered crystalline structure.

The study of the photoluminescence properties is interesting because it can provide valuable information on the quality, purity, and the structural properties of the material. Moreover, recording PL spectrum is of paramount importance for evaluating their optical characteristics for various 
applications. The PL spectra of samples A and B are depicted in Figures 7(a) and 7(b). On sample A, three emission peaks, a blue light at $400 \mathrm{~nm}$, a blue-green around $464 \mathrm{~nm}$, and a green light at around $520 \mathrm{~nm}$, were recorded. The main strong UV emission at $400 \mathrm{~nm}$ corresponds to the nearband-edge emission, while the blue-green and green emission peaks at $464 \mathrm{~nm}$ and $520 \mathrm{~nm}$ are instead possibly associated with oxygen vacancies $[46,47]$. Specifically, the blue-green transition at $464 \mathrm{~nm}$ is caused due to transition from the level of ionized oxygen vacancy to the valence band, while the green emission, called deep-level emission, occurs by the recombination of the photogenerated holes with singly ionized oxygen vacancies in $\mathrm{ZnO}$. On sample $\mathrm{B}$, an additional $\mathrm{UV}$ emission peak at $385 \mathrm{~nm}$, due to the recombination of photogenerated electrons and holes, appears as a shoulder of the main peak at $400 \mathrm{~nm}$. The higher intensity of nearband-edge emission peaks compared to green emission peaks is an indication of the good quality of $\mathrm{ZnO}$ nanostructures produced.

\section{Conclusions}

The morphology, structure, and optical properties of $\mathrm{ZnO}$ nanostructures synthesized by microwave irradiation have been investigated in detail. The composition and morphology of the nanostructures are affected by the presence of albumen as a template. The optical band gap of the polycrystalline $\mathrm{ZnO}$ nanoparticles increases from 3.22 to $3.25 \mathrm{eV}$ for the sample synthesized in the presence of albumen because of the defects' decrease. The good quality of $\mathrm{ZnO}$ nanostructures produced was also demonstrated by PL studies which evidenced a higher intensity of near-band-edge emission peaks compared to green emission peaks. In summary, results obtained indicate that the microwave-assisted method is a promising low temperature, cheap, and fast method for the production of $\mathrm{ZnO}$ nanostructures.

\section{References}

[1] B. B. Rao, "Zinc oxide ceramic semi-conductor gas sensor for ethanol vapour," Materials Chemistry and Physics, vol. 64, no. 1, pp. $62-65,2000$.

[2] W. H. G. Horsthuis, "ZnO processing for integrated optic sensors," Thin Solid Films, vol. 137, no. 2, pp. 185-192, 1986.

[3] Asif, Nur, Willander, and Danielsson, "Selective calcium ion detection with functionalized $\mathrm{ZnO}$ nanorods-extended gate MOSFET," Biosensors and Bioelectronics, vol. 24, no. 11, pp. 3379-3382, 2009.

[4] C. Xia, N. Wang, L. Lidong, and G. Lin, "Synthesis and characterization of waxberry-like microstructures $\mathrm{ZnO}$ for biosensors," Sensors and Actuators B, vol. 129, no. 1, pp. 268-273, 2008.

[5] Krishnamoorthy and Iliadis, "Development of high frequency $\mathrm{ZnO} / \mathrm{SiO} 2 / \mathrm{Si}$ Love mode surface acoustic wave devices," SolidState Electronics, vol. 50, no. 6, pp. 1113-1118, 2006.

[6] Liu, Zhang, Lu et al., "Fabrication and characterization of $\mathrm{ZnO}$ film based UV photodetector," Journal of Materials Science, vol. 20, no. 3, pp. 197-201, 2009.
[7] Y. Wang and M. Li, "Hydrothermal synthesis of singlecrystalline hexagonal prism $\mathrm{ZnO}$ nanorods," Materials Letters, vol. 60, no. 2, pp. 266-269, 2006.

[8] Lee, Easteal, Pal, and Bhattacharyya, "Evolution of $\mathrm{ZnO}$ nanostructures in sol-gel synthesis," Current Applied Physics, vol. 9, no. 4, pp. 792-796, 2009.

[9] Wang, Liu, Chang, and Tang, "Synthesis of sulfur-doped $\mathrm{ZnO}$ nanowires by electrochemical deposition," Materials Science in Semiconductor Processing, vol. 10, no. 6, pp. 241-245, 2007.

[10] J. Park, Y. Choi, and J. Park, "Synthesis of ZnO nanowires and nanosheets by an $\mathrm{O} 2$-assisted carbothermal reduction process," Journal of Crystal Growth, vol. 280, no. 1-2, pp. 161-167, 2005.

[11] H. Cheng, J. Cheng, Y. Zhang, and Q. Wang, "Large-scale fabrication of $\mathrm{ZnO}$ micro-and nano-structures by microwave thermal evaporation deposition," Journal of Crystal Growth, vol. 299, no. 1, pp. 34-40, 2007.

[12] J. Liu, J. Cao, Z. Li, G. Ji, and M. Zheng, "A simple microwaveassisted decomposing route for synthesis of $\mathrm{ZnO}$ nanorods in the presence of PEG400," Materials Letters, vol. 61, no. 22, pp. 4409-4411, 2007.

[13] S. Cho, D. Shim, S. Jung, E. Oh, B. R. Lee, and K. Lee, "Fabrication of $\mathrm{ZnO}$ nanoneedle arrays by direct microwave irradiation," Materials Letters, vol. 63, no. 9-10, pp. 739-741, 2009.

[14] Krishnakumar, Jayaprakash, N. Pinna, Singh, Mehta, and Phani, "Microwave-assisted synthesis and characterization of flower shaped zinc oxide nanostructures," Materials Letters, vol. 63, no. 2, pp. 242-245, 2009.

[15] I. Y. Y. Bu, "Rapid synthesis of $\mathrm{ZnO}$ nanostructures through microwave heating process," Ceramics International, vol. 39, pp. 1189-1194, 2013.

[16] S. T. Aruna and A. S. Mukasyan, "Combustion synthesis and nanomaterials," Current Opinion in Solid State and Materials Science, vol. 12, no. 3-4, pp. 44-50, 2008.

[17] Mohebbi, Ebadzadeh, and Hesari, "Synthesis of nanocrystalline (Ni/NiO)-YSZ by microwave-assisted combustion synthesis method: the influence of $\mathrm{pH}$ of precursor solution," Journal of Power Sources, vol. 178, no. 1, pp. 64-68, 2008.

[18] M. A. Bhosale, K. D. Bhatte, and B. M. Bhanage, "A rapid, one pot microwave assisted synthesis of nanosize cuprous oxide," Powder Technology, vol. 235, pp. 516-519, 2013.

[19] P. Dinka and A. S. Mukasyan, "In situ preparation of oxidebased supported catalysts by solution combustion synthesis," Journal of Physical Chemistry B, vol. 109, no. 46, pp. 21627-21633, 2005.

[20] Kasapoğlu, Baykal, Köseoǧlu, and Toprak, "Microwave-assisted combustion synthesis of $\mathrm{CoFe} 2 \mathrm{O} 4$ with urea, and its magnetic characterization," Scripta Materialia, vol. 57, no. 5, pp. 441-444, 2007.

[21] L. Ai and Jiang, "Rapid synthesis of nanocrystalline Co3O4 by a microwave-assisted combustion method," Powder Technology, vol. 195, no. 1, pp. 11-14, 2009.

[22] Y. Fu, Y. Su, and C. Lin, "Comparison of microwave-induced combustion and solid-state reaction for synthesis of LiMn2$\mathrm{xCrxO} 4$ powders and their electrochemical properties," Solid State Ionics, vol. 166, no. 1-2, pp. 137-146, 2004.

[23] A. Srivastava, Lakshmikumar, Srivastava, Rashmi, and K. Jain, "Gas sensing properties of nanocrystalline $\mathrm{SnO} 2$ prepared in solvent media using a microwave assisted technique," Sensors and Actuators B, vol. 126, no. 2, pp. 583-587, 2007. 
[24] Y. Fu, Y. Chang, and S. Wen, "Microwave-induced combustion synthesis and electrical conductivity of Ce1-xGdxO2-1/2x ceramics," Materials Research Bulletin, vol. 41, no. 12, pp. 2260 2267, 2006.

[25] E. Esmaeili, A. Khodadadi, and Y. Mortazavi, "Microwaveinduced combustion process variables for $\mathrm{MgO}$ nanoparticle synthesis using polyethylene glycol and sorbitol," Journal of the European Ceramic Society, vol. 29, no. 6, pp. 1061-1068, 2009.

[26] C. Hwang and T. Wu, "Combustion synthesis of nanocrystalline $\mathrm{ZnO}$ powders using zinc nitrate and glycine as reactants Influence of reactant composition," Journal of Materials Science, vol. 39, no. 19, pp. 6111-6115, 2004.

[27] M. Selvakumar and D. K. Bhat, "Microwave synthesized nanostructured $\mathrm{TiO}_{2}$-activated carbon composite electrodes for supercapacitor Selvakumar," Applied Surface Science, vol. 263, pp. 236-241, 2012.

[28] I. Bilecka, P. Elser, and M. Niederberger, "Kinetic and thermodynamic aspects in the microwave-assisted synthesis of $\mathrm{ZnO}$ nanoparticles in benzyl alcohol," ACS Nano, vol. 3, no. 2, pp. 467-477, 2009.

[29] P. Zhu, J. Zhang, Z. Wu, and Z. Zhang, "Microwave-assisted synthesis of various $\mathrm{ZnO}$ hierarchical nanostructures: effects of heating parameters of microwave oven," Crystal Growth and Design, vol. 8, no. 9, pp. 3148-3153, 2008.

[30] N. F. Hamedani, A. R. Mahjoub, A. A. Khodadadi, and Y. Mortazavi, "Microwave assisted fast synthesis of various $\mathrm{ZnO}$ morphologies for selective detection of $\mathrm{CO}, \mathrm{CH} 4$ and ethanol," Sensors and Actuators B, vol. 156, no. 2, pp. 737-742, 2011.

[31] J. ZHU, J. ZHANG, H. ZHOU, W. QIN, L. CHAI, and Y. HU, "Microwave-assisted synthesis and characterization of $\mathrm{ZnO}$ nanorod arrays," Transactions of Nonferrous Metals Society of China (English Edition), vol. 19, no. 6, pp. 1578-1582, 2009.

[32] Savary, Marinel, Colder, Harnois, Lefevre, and Retoux, "Microwave sintering of nano-sized $\mathrm{ZnO}$ synthesized by a liquid route," Powder Technology, vol. 208, no. 2, pp. 521-525, 2011.

[33] L. C. Nehru, V. Swaminathan, and C. Sanjeeviraja, "Rapid synthesis of nanocrystalline $\mathrm{ZnO}$ by a microwave-assisted combustion method," Powder Technology, vol. 226, pp. 29-33, 2012.

[34] Al-Hajry, A. Umar, Hahn, and Kim, "Growth, properties and dye-sensitized solar cells-applications of $\mathrm{ZnO}$ nanorods grown by low-temperature solution process," Superlattices and Microstructures, vol. 45, no. 6, pp. 529-534, 2009.

[35] T. Prakash, R. Jayaprakash, D. Sathya Raj et al., "Sensing properties of $\mathrm{ZnO}$ nanoparticles synthesized by using albumen as a biotemplate for acetic acid monitoring in aqueous mixture," Sensors and Actuators B, vol. 176, pp. 560-568, 2013.

[36] Vafaee and M. S. Ghamsari, "Preparation and characterization of $\mathrm{ZnO}$ nanoparticles by a novel sol-gel route," Materials Letters, vol. 61, no. 14-15, pp. 3265-3268, 2007.

[37] A. Umar, Rahman, M. Vaseem, and Y. Hahn, "Ultra-sensitive cholesterol biosensor based on low-temperature grown $\mathrm{ZnO}$ nanoparticles," Electrochemistry Communications, vol. 11, no. 1, pp. 118-121, 2009.

[38] A. Umar, Rahman, Al-Hajry, and Hahn, "Highly-sensitive cholesterol biosensor based on well-crystallized flower-shaped ZnO nanostructures," Talanta, vol. 78, no. 1, pp. 284-289, 2009.

[39] A. E. Morales, E. S. Mora, and U. Pal, "Use of diffuse reflectance spectroscopy for optical characterization of unsupported nanostructures," Revista Mexicana De Fisica S, vol. 53, pp. 18-22, 2007.
[40] Senthilkumar, Vickraman, and Ravikumar, "Synthesis of fluorine doped tin oxide nanoparticles by sol-gel technique and their characterization," Journal of Sol-Gel Science and Technology, vol. 53, no. 2, pp. 316-321, 2010.

[41] F. Yakuphanoglu, "Electrical characterization and device characterization of $\mathrm{ZnO}$ microring shaped films by sol-gel method," Journal of Alloys and Compounds, vol. 507, no. 1, pp. 184-189, 2010.

[42] Yakuphanoglu, Mehrotra, Gupta, and M. Oz, "Nanofiber organic semiconductors: the effects of nanosize on the electrical charge transport and optical properties of bulk polyanilines," Journal of Applied Polymer Science, vol. 114, no. 2, pp. 794-799, 2009.

[43] J. Tauc, R. Grigorovici, and A. Vancu, "Optical properties and electronic structure of amorphous germanium," Physica Status Solidi B, vol. 15, pp. 627-637, 1966.

[44] Wang, Chen, and Yang, "Microstructure and optical properties of polycrystalline $\mathrm{ZnO}$ films sputtered under different oxygen flow rates," Journal of Alloys and Compounds, vol. 488, no. 1, pp. 232-237, 2009.

[45] A. K. Zak, M. E. Abrishami, W. H. Abd Majid, R. Yousefi, and S. M. Hosseini, "Effects of annealing temperature on some structural and optical properties of $\mathrm{ZnO}$ nanoparticles prepared by a modified sol-gel combustion method," Ceramic International, vol. 37, pp. 393-398, 2011.

[46] P. Yang, H. Yan, S. Mao et al., "Controlled growth of $\mathrm{ZnO}$ nanowires and their optical properties," Journal of Advanced Functional Materials, vol. 12, pp. 323-331, 2002.

[47] P. Jiang, J. Zhou, H. Fang, C. Wang, Z. L. Wang, and S. Xie, "Hierarchical shelled $\mathrm{ZnO}$ structures made of bunched nanowire arrays," Advanced Functional Materials, vol. 17, no. 8, pp. 1303-1310, 2007. 

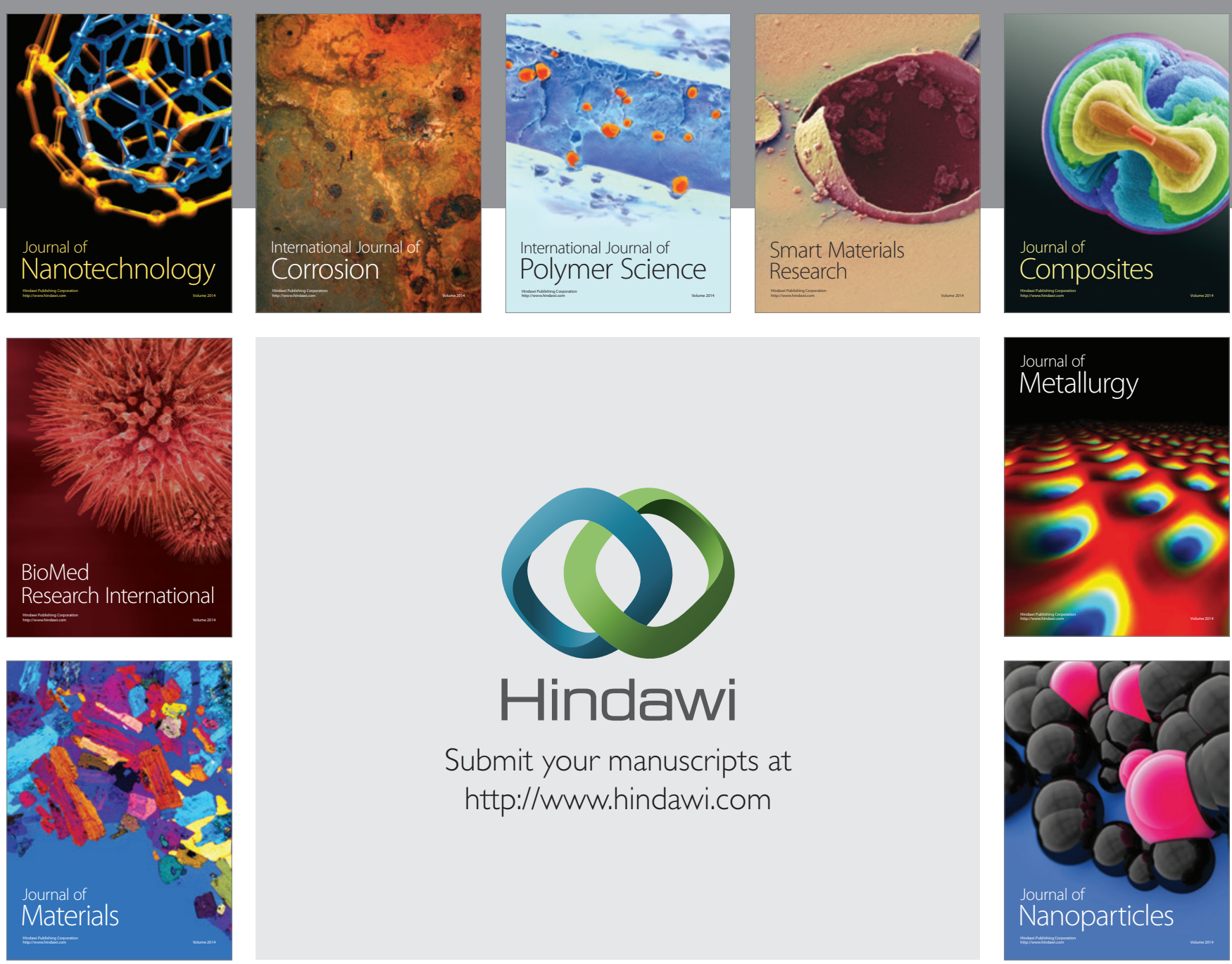

Submit your manuscripts at http://www.hindawi.com
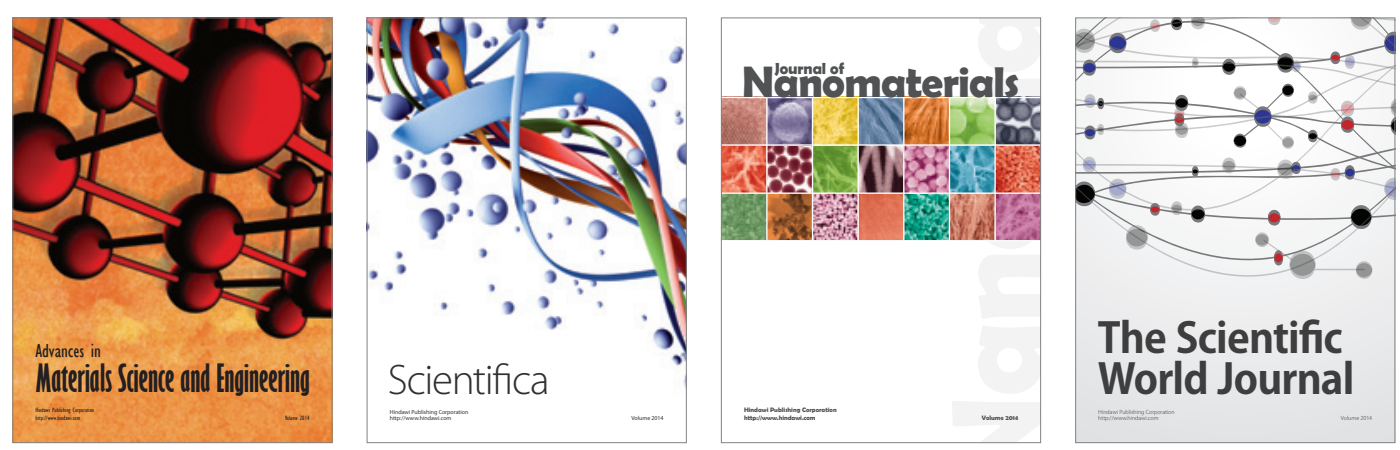

\section{The Scientific World Journal}
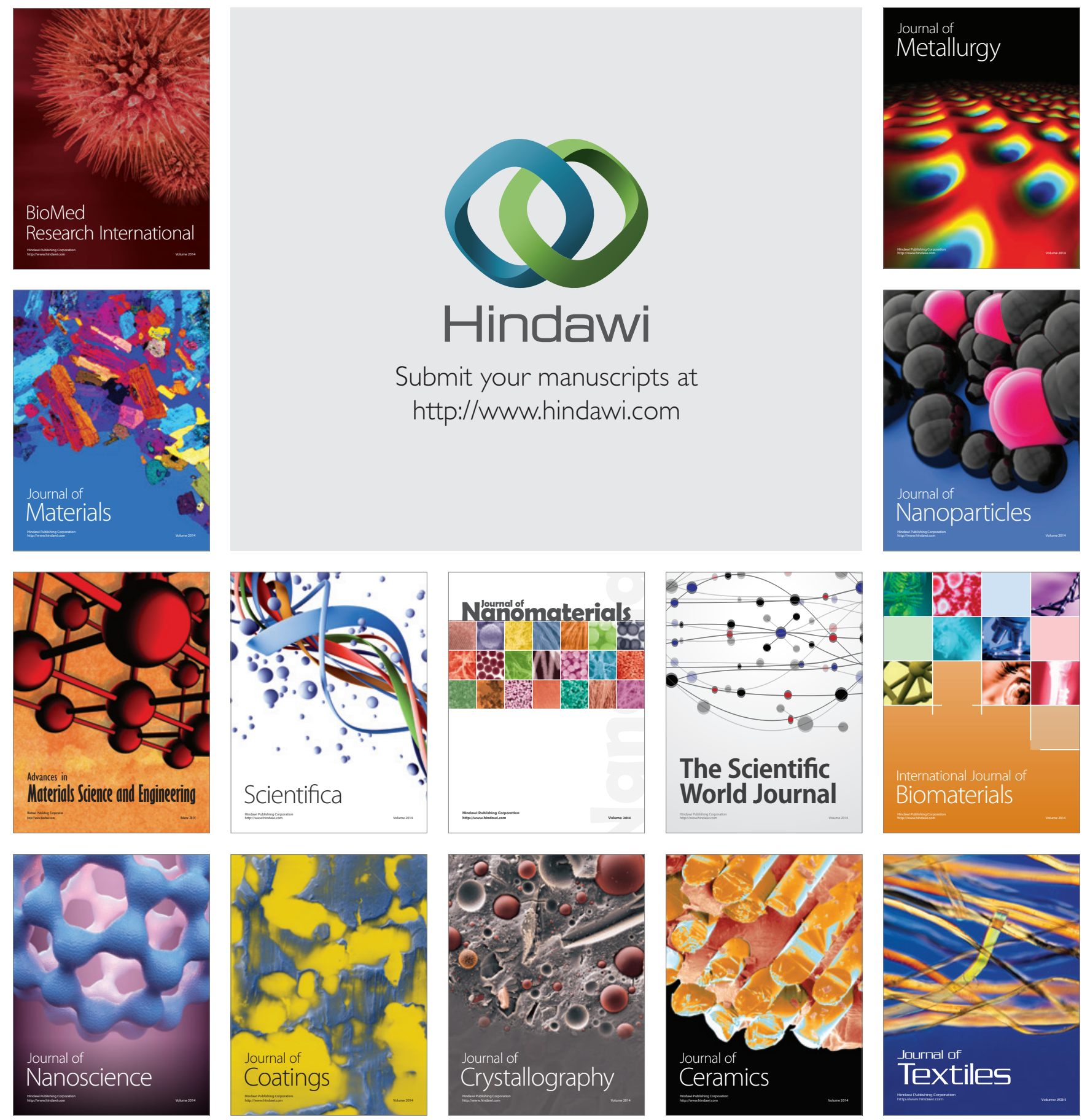